\title{
Kolluk Kuvvetleri Tarafından Yapılan Araç Denetimlerindeki Verimliliğinin Artırılmasını Amaçlayan Plaka Tanıma Sistemi
}

\author{
Rumeysa Çelik $^{1^{*}}$, Kemal Erdoğan ${ }^{1}$ \\ ${ }^{1 *}$ Konya Teknik Üniversitesi, Mühendislik Ve Doğa Bilimleri Fakültesi, Elektrik Elektronik Mühendisliği Bölümü, Konya, Türkiye, (ORCID:0000-0002-0064-3706), \\ rumeysacelik961@gmail.com \\ ${ }^{1}$ Konya Teknik Üniversitesi, Mühendislik Ve Doğa Bilimleri Fakültesi, Elektrik Elektronik Mühendisliği Bölümü, Konya, Türkiye, (ORCID:0000-0001-7433-2516), \\ kerdogan@ktun.edu.tr
}

(2nd International Conference on Computer, Electrical and Electronic Sciences ICCEES 2021, September 1-3, 2021)

(DOI: 10.31590 /ejosat.)

ATIF/REFERENCE: Çelik, R. \& Erdoğan, K. (2021). Kolluk Kuvvetleri Tarafından Yapılan Araç Denetimlerindeki Verimliliğinin Artırılmasını Amaçlayan Plaka Tanıma Sistemi. Avrupa Bilim ve Teknoloji Dergisi, (30), 62-65.

\begin{abstract}
Öz
Yapılan bu çalışmada amaç kolluk kuvvetleri tarafından yapılan araç denetimlerinin verimliliğinin artırılmasıdır. Özellikle trafik akışının yoğun olduğu bölgelerde tüm araçlarda inceleme yapılamadığından dolayı denetimlerin verimliliği düşmektedir. Nizami bir aracın seyahat halinde iken birden çok kontrol noktasında tekraren durdurulmasının önüne geçilmesini, hakkında ihbarda bulunulmuş plakaya sahip aracın tespit edilen ilk noktada muhakkak durdurulmasını hedefleyerek denetimlerin verimliliğini artırmak hedeflenmiştir. Tasarlanan bu sistemde görüntü işleme ve KNN gibi teknikler ile okunan plaka tarih bilgisi ile veri tabanına kaydedilmekte, plakanın önceki son görüntülendiği tarihe göre hesaplama yapılmakta ve denetim noktasından sık sık geçen araçların ekstra denetiminin yapılmasının önüne geçilmektedir. Bu sayede denetim yapan ekibin işi kolaylaştırılmakta, aynı bölge içerisindeki nizami araçların sık sık denetime girmesinin önüne geçilmekte ve bazı sürücüler için de zaman kaybı oluşması önlenmektedir. Yapılan denemelerde gerçek zamanlı çalışan KNN ile plaka tanıma sisteminde yaklaşık olarak \%67 doğruluk oranı tespit edilmiştir. Sistemin daha başarılı çalışabilmesi plaka tanıma işi için derin öğrenme metotlarının kullanılması önerilmektedir.
\end{abstract}

Anahtar Kelimeler: Görüntü Işsleme, KNN, Mobil Emniyet Teknolojileri, Plaka Tanıma, Suç Önleme.

\section{License Plate Recognition System Aiming to Increase Efficiency in Vehicle Inspections by Law Enforcement Forces}

\begin{abstract}
The aim of this study is to increase the efficiency of vehicle inspections by law enforcement officers. Especially in areas with heavy traffic flow, the efficiency of inspections decreases as all vehicles cannot be inspected. It is aimed to increase the efficiency of inspections by aiming to prevent a legal vehicle from being stopped again at more than one check point while traveling, and to stop the vehicle with the reported plate at the first detected point. In this designed system, the license plate read with techniques such as image processing and $\mathrm{KNN}$ is recorded in the database with date information, calculations are made according to the date the license plate was last viewed, and extra inspections of vehicles that frequently pass through the inspection point are prevented. In this way, the work of the inspection team is simplified, frequent inspections of legal vehicles in the same region are prevented, and time loss for some drivers is prevented. In the trials, approximately $67 \%$ accuracy rate was determined in the license plate recognition system with real-time working KNN. It is recommended to use deep learning methods for license plate recognition for the system to work more successfully.
\end{abstract}

Keywords: Crime Prevention, Image Processing, KNN, Mobile Security Technologies, License Plate Recognition.

\footnotetext{
* Sorumlu Yazar: rumeysacelik961@gmail.com
} 


\section{Giriş}

Araçlar için plakalar birer kimlik numarasıdır. Dolayısıyla plakaların tanınması birçok açıdan önem taşımaktadır. Özellikle giriş çıkış sınıflandırılması, otoparklar, yollar vb. yerlerde görüntü işleme ile plaka tanıma sistemlerine güvenlik ve denetim açısından oldukça fazla ihtiyaç duyulmaktadır. İşlemlerin bilgisayar ile yapılması hem işlem süresini kısaltmakta hem de güvenirliğini arttırmaktadır. Emniyet teşkilatı da teknolojiden en üst seviyede faydalanmayı amaçlayan dijital teknolojilerin geliştirilmesini ve güvenlik denetimlerinde kullanılmasını hedeflemektedir.(Ninla Elmawati Falabiba, 2019) Ülkemizde kolluk kuvvetlerinin ulaşım noktalarında yaptığı güvenlik denetimleri yoğun bir şekilde gerçekleştirilmektedir. Emniyet Genel Müdürlüğü verilerine göre sadece 2019 yılı temmuz ayında 182987 araç denetlenmiştir (egm, 2021). Bu denetimlerdeki yoğunluk nedeniyle çoğu zaman o noktadan geçen tüm araçların incelenemediği bilinmektedir. $\mathrm{Bu}$ durumda gerekli kontroller veya sorgulamalar yapılırken hangi araçların seçilip durdurulacağı konusunda yardımcı olacak herhangi bir teknik ekipmandan faydalanıldığına dair bir kaynak bulunamamıştır. Kontrol edilecek araç seçimi yapılırken görevli personelin tecrübesinin, kontrol noktasına gelen aracın görünümünün veya şüpheli hareketlerinin etkisi olduğu düşünülebilir. Seyahat halindeki bir aracın aynı seyahat esnasında birden fazla kontrol noktasında tekraren durdurulması, ya da birkaç günlük kısa zaman aralıklarında aynı kontrol noktasından birden fazla kez geçerken tekraren durdurulması denetimlerde verimsizliğe yol açmaktadır. $\mathrm{Bu}$ çalışmada bahsedilen verimsizliğin önüne geçilmesini sağlayacak bir sistem hazırlanmıştır.

Çalışmada denetim noktasına gelen araçların görüntü işleme teknikleriyle okunan plakalarının saat ve tarih bilgisiyle birlikte veri tabanına kaydedilmesi; en son görüntülenme tarihiyle arasında ne kadar zaman farkı olduğunun hesaplanması ve gelen aracın belirlenen süre zarfında tekrar kontrol edilmesine gerek kalıp kalmadığını bildirmesi amaçlanmıştır. Ayrıca oluşturulan veri tabanına şüpheli veya hakkında ihbarda bulunulmuş bir araç plaka bilgisi girilmiş ise görevli personelin uyarılarak denetim yoğunluğu olsa bile ilgili aracın muhakkak durdurulması da sağlanabilecektir.

Hazırlanan sistemde plaka tanıma işlemi görüntü işleme ile gerçek zamanlı olarak gerçekleşmekte ve gerçek zamanlı görüntü IP kameradan alınmaktadır. Literatürde derin öğrenme ile plaka tanımanın yapıldığı ve \%98'e varan başarım sağlayan çalışmalar bulunmaktadır (Bayram, 2019)(Quiros et al., 2017).

Veri tabanı ise python programlama dili kullanılarak MySQL workbench $8.0 \mathrm{CE}$ veri tabanı ara yüzü ile bağlantı kurularak tasarlanmış ve okunan plakalar oluşturulan tabloya eklenmiştir.

\section{Materyal ve Metot}

\subsection{Plakanın Okunması}

Çalışma yapılırken OpenCV (Open Source Computer Vision) açık kaynak kodlu görüntü işleme kütüphanesi kullanılmıştır. Kameradan elde edilen görüntü verilerine karakter tanımlama uygulanmadan önce kontrast genleştirme, görüntüyü gri seviyeye dönüştürme, resim yumuşatma ve gürültüyü azaltmak için eşikleme işlemleri uygulanmıştır. Daha sonra segmantasyon işlemleri yapılarak olası karakterlerin tespit edilmesi işlemine geçilmiştir. Bu işlemlerde yüksek başarım oranına sahip ve basit bir algoritma olan KNN (K-En Yakın Komşu Algoritması)'dan faydalanılmıştır.

Plaka tanıma sisteminde görüntü işleme şu şekilde gerçekleştirilmiştir.

İlk olarak renkli görüntü gri seviyeli görüntüye çevrilmektedir. $\mathrm{Bu}$ adım sayesinde görüntü üzerinde gerçekleştirilecek işlemler daha kolay gerçekleştirilmektedir.

Daha sonra gri seviyeli görüntü ikili görüntüye dönüştürülür ve morfolojik dönüşümler uygulanır. Oluşan görüntü üzerine gaussian blur filtresi uygulanarak görüntü yumuşatılmıştır. Bu görüntü üzerinde tüm konturların bulunmuş ve eşlenen tüm karakterler listelenmiştir. Daha sonra ise tüm plakalar listelenmiş ve plaka olmaya en müsait kısım çıkartılmıştır. Bu plaka orijinal görüntüden kırpılmakta ve görüntü işlemenin basamakları tekrar bu çıkartılmış plaka üzerinde uygulanmaktadır. Plakadaki karakter ve sayıyı tanımak için karakterler ve sayılar bölütlenmekte ve KNN'nin eğitim verileriyle eşleşerek sonucu çıktı olarak vermektedir.

\subsection{Veri Tabanı Oluşturulması}

Plaka okuması başarı ile sağlandıktan sonra plaka ve zaman bilgisi oluşturulan veri tabanına kaydedilmektedir.

Veri tabanı oluşturulmak için Mysql Workbench ara yüzü ile bağlantı kurulmuş gerekli kullanıcı adı ve şifre kullanılarak veri tabanı tasarlanmıştır. Bu veri tabanında içerisinde plaka ve tarih sütunlarının yer aldığı tablo oluşturulmuş ve okunan plaka görüntülendiği tarih bilgisiyle birlikte bu tablo içerisine kaydedilmiştir (Şekil-1).

\subsection{Plakaların Görüntülenme Zaman Farkları ve Şüpheli Plaka Denetimi}

Veri tabanına kaydedilen plakalardan o anda okunan plakaya ait görüntülenme zamanları alınmakta ve bir önceki görüntülenme ile en son görüntülenme arasındaki zaman farkı hesaplanmaktadır. Tespit edilen araç plakası ilk defa görüntüleniyorsa "ilk defa görüntüleniyor” bilgisi verilmektedir. Tespit edilen araç daha önce sisteme şüpheli araç olarak tanıtılmış ise "şüpheli araç bilgisi” veya şüpheli değil ise şüpheli olmadığına dair “-” işareti görüntülenmektedir. Bu bilgiler PyQt5 programı ile ekranda görüntülenmektedir (Şekil-2).

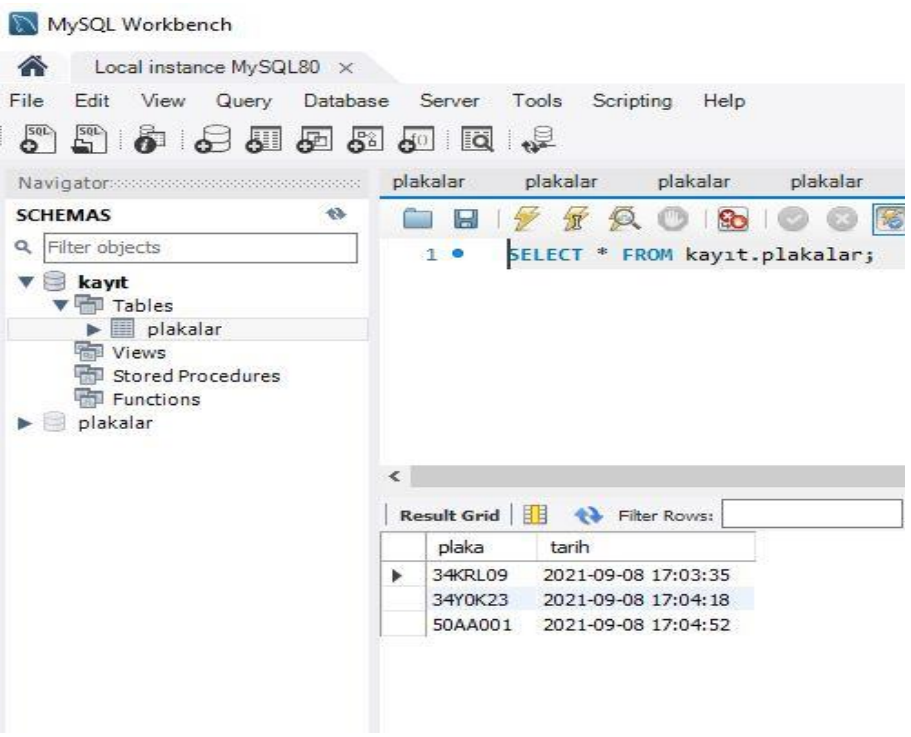

Şekil 1. Araç plaka ve tarih bilgisinin kaydedilmesi 


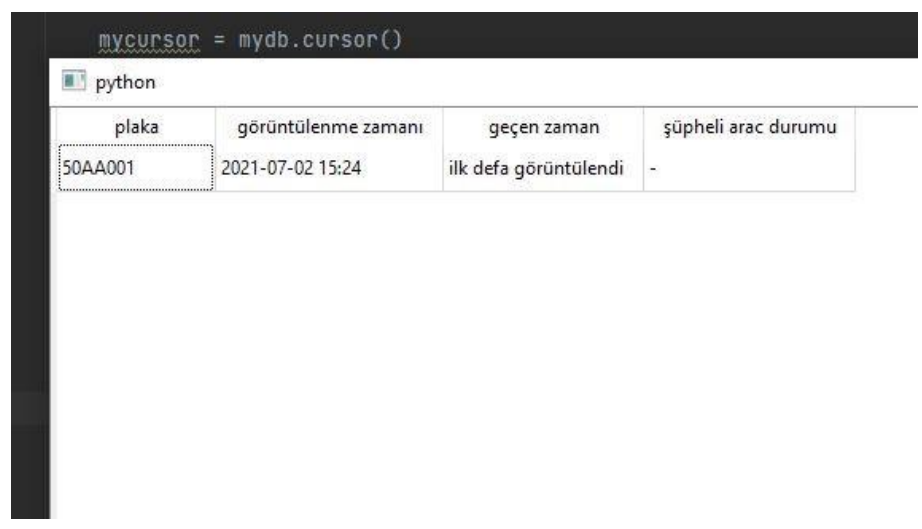

Şekil 2. Tespit edilen araç plakası hakkındaki uyarı bilgilerinin görüntülenmesi

PyQt, Qt şirketinin, Qt uygulama çerçevesinde Python versiyon 2 ve versiyon 3 için ürettiği bir ara yüz olup Windows, OS X, Linux, iOS ve Android de dahil olmak üzere Qt tarafından desteklenen tüm platformlarda çalışabilmektedir. PyQt5, Qt v5'i desteklerken PyQt4, Qt v4'ü desteklemektedir. Ara yüz bağlamaları bir dizi Python modülü olarak uygulanır ve 1000 'den fazla sınıf içermektedir.

PyQt, Qt C++ çapraz platform uygulama çerçevesini ve çapraz platform tarafindan yorumlanan Python dilini bir araya getirmektedir. (cozum pedia, 2021)

Hazırlanan sistemde bazı plaka resimleri IP kameraya gösterilerek 600x600 boyutlarında gerçek olarak tanımlanması yapılmıştır. Program sadece dikdörtgen şeklindeki plakaları tanımlayacak şekilde python programlama dili kullanılarak tasarlanmıştır. Yazılımın gerçekleştirildiği ve test edildiği bilgisayar 16 GByte ram, i7-10750H işlemciye sahiptir. Sistemin plaka yeri tespit etmekte çoğunlukla başarılı olduğu görülmüş fakat plaka tanımlamada plaka resminin boyutuna ve görüntülen mesafeye bağlı olarak başarı oranın etkilendiği tespit edilmiştir.

Literatürdeki bulunan diğer çalışmaların başarı oranları Tablo.1'de verilmiştir.

\section{Araştırma Sonuçları ve Tartışma}

Çalışmada KNN yöntemiyle gerçek zamanlı olarak plaka tespit edilmektedir. KNN algoritmasıyla okunan karakterlerin en yakın olduğu harf ve rakamlar belirlenmekte ve plaka bilgisinin nihai hali oluşturulmaktadır. Plaka bilgileri plaka listesi veri tabanına eklenmekte ve ihtiyaç duyulduğunda buradan plakanın seçimi yapılarak sonuca varılmaktadır. Fotoğraf üzerinde plaka belirlemede yaklaşık \%90 başarı sağlayan bu sistem gerçek zamanlı olarak plaka belirlenmesinde kullanıldığında başarı oranının düştüğü görülmektedir. Bu durumda plakanın boyutuna bağlı olarak gerekli KNN yaklaşım ayarlamaları yapılarak düzeltilmeler yapılması gerekmektedir. Fakat bu ayarlamaların her plaka boyutu için ayrı ayrı yapılması zor olduğundan hemen hemen aynı plaka boyutlarında daha doğru okumalar yaparken farklı plaka boyutlarında okumanın tam gerçekleşmediği görülmektedir. Sistemde bazen plaka üzerinde takılmalar meydana geldiği bu da plakanın birden fazla kez okunmasına yani bir önceki görüntülenme zamanı ile arasındaki geçen zaman farkının yanlış hesaplanmasına sebep olduğu görülmüştür. Bunun için ise plakanın çok kısa bir zamanda ekranda görülmesi gerektiği öngörülmüştür.

Ayarlanan parametreleri sonucu daha çok doğru okumanın, hemen hemen aynı boyuttaki plaka resimlerinde daha doğru sonuç verdiği plaka boyunun daha fazla büyümesi ve daha çok küçültülmesiyle okumanın daha zorlaştığı görülmüştür. Bu ise sistemin her mesafeden plaka okuması yapmasının pek mümkün olmadığı, sadece ayarlanan ve sabitlenen bir yerde belirli bir mesafede kullanılmasının uygun olduğu anlamına gelmektedir. Bunun yanı sıra sistemin bazı birbirine benzer harf ve rakamları sık olarak karıştırdığı (örneğin 1 harfi ile 1 arasında ,0, D, O vb.) bununda haliyle plakanın yanlış okunmasına, şüpheli araç bulunmasında veya zaman farkı hesaplamasında hatalara yol açtı̆̆ı görülmektedir.

Tablo 1. Literatürdeki bazı plaka tanıma çalışmalarının başarı oranları

\begin{tabular}{c|c|c}
\hline Plaka Tanıma ile İlgili Çalışmalar & Kullanılan Yöntemler & Başarı Oranı (\%) \\
\hline Bayram F. & Mask-RCNN & 98.46 \\
\hline Zhuang ve ark. & DeepLabv2 ResNet-101 model & 99.25 \\
\hline Bingöl ve ark. & Şablon eşleme & 87 \\
\hline Rasheed ve ark. & Hough çizgileri, Şablon Eşleme & 89.70 \\
\hline Li ve ark. & Öznitelik Çıarma, Kenar Bulma & $\% 97.06$ \\
\hline
\end{tabular}


Sistem Şekil-3'te gösterilen 21 plaka üzerinde denenmiştir. Bunlardan 7 tanesinde hatalı veya eksik plaka okuma gözlemlenmiş olup \%67 gibi bir doğruluk oranıyla plakanın tespit edilebildiği görülmüştür. Daha yüksek başarı sağlayabilmek için önerilen ise bu tür plaka okuma sistemlerinde KNN gibi daha basit bir makine öğrenmesi yerine daha gelişmiş öğrenme yöntemlerinin kullanılarak sistemin tasarlanmasıdır.
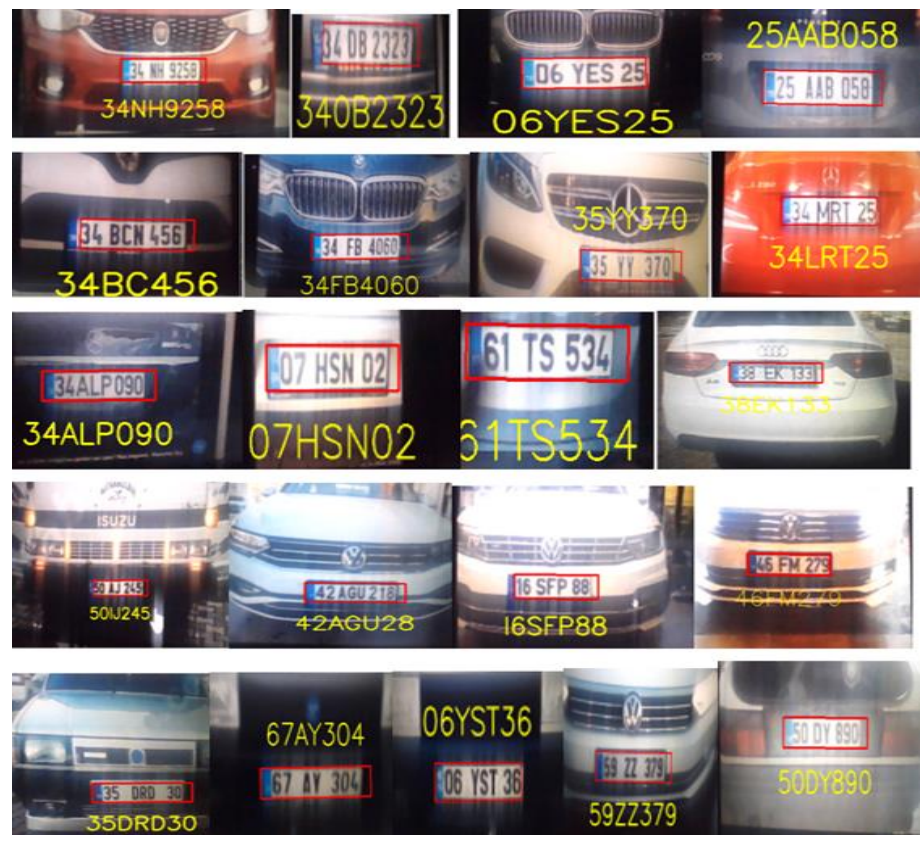

Şekil 3. Sistem üzerinde yapılan plaka tespit denemeleri.

\section{Sonuç}

Sistemin çalışması IP kameraya gösterilen ve dosya üzerinden okunan bazı plaka resimleri ile denenmiştir. Sistemin gerçek başarım oranının elde edilebilmesi için trafik akan bir yolda denemelerin yapılması ve elde edilen görüntüye ve bazı parametrelere göre algoritmada ayarlamaların yapılması gerekmektedir.

Çalışma sonucunda denetim noktasına gelen araçların görüntü işleme teknikleriyle okunan plakalarının zaman bilgisiyle birlikte veri tabanına kaydedilmesini sağlayabilecek bir sistem gerçekleştirilmiştir. En son denetim tarihiyle o anki tespitin arasında ne kadar zaman farkı olduğunun hesaplanması ve gelen aracın belirlenen süre zarfında tekrar kontrol edilmesine gerek kalıp kalmadığının bildirilmesiyle birlikte denetimlerin verimliliğinin artırılabileceği düşünülmektedir. Ayrıca oluşturulan veri tabanına şüpheli veya hakkında ihbarda bulunulmuş araç plaka bilgisi girilebilmesi sayesinde denetim esnasında yoğunluk olsa bile görevli personelin uyarılması sağlanabilecek yine bu sayede denetim verimliliğinin artırılmasına katkıda bulunulabilecektir.

Gelecek çalışması olarak, Yapay Sinir Ağları gibi farklı mimarideki sınıflandırma metotlarının kullanılmasıyla denemelerin yapılması başarı oranlarındaki değişimlerin gözlemlenmesi faydalı olacaktır. Ayrıca gerçek bir uygulama noktasında sistemin denenmesi ve klasik yönteme göre farklarının ortaya konulması da verimlilik başarısının ölçülmesini sağlayabilecektir.

\section{Kaynakça}

Çatal M. (2019). Mobil Emniyet Uygulamalarına Yönelik Bir İnceleme: METE Örneği, "Dijital Çă̆da Güvenliğin Dönüşümü ve Bir İç Güvenlik Aktörü Olarak Polis" Sempozyuти. pp 79-93, İstanbul, Türkiye, 2019.

Emniyet Genel Müdürlüğü websitesi. (2021). 29 Ağustos 2021 tarihinde http://www.egm.gov.tr/temmuz adresinden erişildi.

Zhuang J., Hou S., Wang Z. ve Zha Z. J. (2018) Towards HumanLevel License Plate Recognition. Ferrari V., Hebert M., Sminchisescu C., Weiss Y. (eds) Computer Vision - ECCV 2018. ECCV 2018. Lecture Notes in Computer Science, vol 11207. Springer, Cham. https://doi.org/10.1007/978-3-03001219-9_19.

Ngöl, O. B. İ., ve Cu, Ö. K. U. Ş. (2008). Bilgisayar Tabanlı Araç Plaka Tanıma Sistemi. Bilişim Teknolojileri Dergisi, 1(3), 0. https://doi.org/10.17671/btd.04928

Rasheed S., Naeem A. ve Ishaq O. (2012). Automated number plate recognition using hough lines and template matching. Proceedings of World Congress Engineering Computer Science, pp. 199-203

Li, B., Tian, B., Li, Y. and Wen, D. (2013). Component-based license plate detection using conditional random field model. IEEE Transactions on Intelligent Transportation Systems, 14(4):1690-1699

Bayram, F. (2019). Derin Öğrenme Tabanlı Otomatik Plaka Tanıma. Journal of Polytechnic, 0900(4), 955-960. https://doi.org/10.2339/politeknik.515830

Quiros, A. R. F., Bedruz, R. A., Uy, A. C., Abad, A., Bandala, A., Dadios, E. P., Fernando, A., ve Salle, D. La. (2017). A kNNbased approach for the machine vision of character recognition of license plate numbers. IEEE Region 10 Annual International Conference, Proceedings/TENCON, 2017December, 1081-1086. https://doi.org/10.1109/TENCON.2017.8228018

CozumPedia websitesi. (2021). 29 Ağustos 2021 tarihinde https://cozumpedia.com/pyqt-nedir adresinden erişildi. 